\title{
A Qualitative Study on the Digital Preservation of OER
}

Sarah Hare and Madison Sullivan

\begin{abstract}
Libraries continue to spearhead initiatives to incentivize instructors to adopt, adapt, and create open educational resources (OER). However, these programs often do not explicitly require instructors to preserve the OER they create. Drawing on an analysis of semistructured interviews with six experts, this article presents considerations for libraries interested in preserving OER and recommendations for OER librarians that are new to digital preservation. The study makes an argument for why and how libraries could begin to preserve OER. Future areas of investigation include better understanding how OER repositories preserve OER and consortia models to support this work.
\end{abstract}




\section{Introduction}

Open educational resources (OER) are learning objects shared under an intellectual property license that explicitly allows others to retain, reuse, revise, remix, and redistribute them. ${ }^{1}$ Examples of OER include textbooks, videos, syllabi, and lectures shared under a Creative Commons license. OER have been widely discussed in recent years as a potential solution to the rising cost of course materials, which are estimated to cost full-time undergraduate students almost $\$ 1,300$ per year. ${ }^{2}$ In addition to cost savings, OER continue to be connected to student retention and course completion. For example, a study at Virginia State University found that students who took courses that utilized OER "tended to have higher grades and lower failing and withdrawal rates." 3

It has become a trend for libraries to spearhead OER initiatives ${ }^{4}$ with successful programs implemented at the University of Massachusetts-Amherst, UCLA, the University of Kansas, Temple University, and the University of Minnesota, among others. ${ }^{5}$ Several libraryled OER initiatives incentivize faculty creation of OER, often by offering stipends to compensate faculty for their time and entice them to participate. In these initiatives, librarians assist faculty with rights checking, project management, finding content, and editing in order to successfully create new OER. ${ }^{6}$

While librarians' expertise in copyright, open access, metadata, and instructional design is often seen as integral for creating new OER, digital preservation is rarely mentioned as an area of expertise that librarians contribute to the open education movement. Academic libraries that are committed to long-term preservation could require or at least encourage preservation of the content they pay faculty to create. There are several reasons to consider preservation. The most obvious is accountability: if library resources are dedicated to incentivizing OER creation, including monetary resources, the resulting materials should be 
available long term. Are we being responsible with our funding if we financially incentivize faculty to create OER that may not be accessible in a few years? When compared to other learning objects, OER have an increased potential to impact outside educators and institutions because of how they are licensed, making them a preservation priority. OER developed as part of a grant are also usually representative of the teaching and learning activities of a particular university or college, making them an important priority within university records management plans. For example, in addition to demonstrating pedagogical innovations happening at a particular time, OER developed as part of a library incentive program are usually key to the curriculum and must be used in classes that reach hundreds of students to be supported by the library. The decision to preserve or not preserve OER will shift based on local priorities, resources, institutional capacity, and context. While this article hopes to provoke thought and provide a starting point for libraries interested in preserving OER, preserving OER is ultimately the decision of individual institutions and library preservation departments.

This article investigates whether library incentive programs to create OER consider digital preservation. In addition to gauging what libraries are currently doing, the article addresses several research questions:

- If OER creation initiatives spearheaded by libraries do not require digital preservation of content, what do they require? Are there specific repositories, Creative Commons licenses, or file formats faculty must use as part of the program?

- If libraries were to systematically pursue the preservation of born-digital OER, what might good practices look like?

- In 2014, David Wiley created a litmus test for determining if a learning object is an OER, holding that other educators must be able to retain, reuse, revise, remix, and 
redistribute it. ${ }^{7}$ What specific preservation challenges arise when other educators utilize these $5 \mathrm{R}$ permissions to their fullest extent?

In addition to the reasons for preserving OER listed above, librarians must consider how openness relies on access. Copyright constraints are not the only barrier to OER adoption and re-mixing: obsolete or proprietary file formats, software requirements, and the need for technical expertise continue to impede the success of the open education movement and educators' ability to utilize the license objects are shared under fully. This article holds that librarians' commitment to digital preservation of content is integral to making sure that OER are open for years to come.

\section{Literature Review}

\section{Digital Preservation}

"The default for digital information is not to survive unless someone takes conscious action to make them persist." - Howard Besser ${ }^{8}$

Digital preservation scholarship and literature has continued to grow significantly since the 1980s. While there are still unknowns, obstacles, and solutions to be developed in the field, there is a breadth of publications to explore. Nevertheless, explicit mention of OER within digital preservation literature is scarce.

Digital preservation is defined as "a series of management policies and activities necessary to ensure the enduring usability, authenticity, discoverability, and accessibility of content over the very long term." "In practice, digital preservation provides a set of guidelines to inform how institutions can approach preserving born-digital or digitized materials and assets. These materials can include websites, audio-visual materials, digital text and images, databases, e-mail, and geospatial data, among other formats. While some paper materials can 
last for decades with minimal attention, digital materials can have a much shorter shelf-life if ignored. These various information formats and content types can sometimes pose different concerns when building a digital preservation strategy. This is particularly true for interactive works. For example, Jasmine Mulliken describes three options for preserving interactive digital content, each with its own challenges: repository deposit, which creates user experience challenges; web archiving, which relies on external entities; and emulation, which is still being developed. ${ }^{10}$ Emulation requires using a software program in an attempt to closely replicate a digital environment or digital object for preservation purposes. ${ }^{1}$ This helps retain the original look and feel of a digital object.

Institutions will have different approaches to digital preservation based on their context, funding, policies, expertise, user needs, and preservation goals. What may be good practice at one institution will not be sufficient, or fully possible, at another. While it is outside the scope of this article to provide a comprehensive overview of digital preservation, OER practitioners looking to delve into digital preservation literature as a novice may find guides such as the Digital Preservation Coalition's "Digital Preservation Handbook," 11 and Maxine K. Sitts' “Handbook for Digital Projects: A Management Tool for Preservation and Access" 12 helpful. "Preserving Digital Information, Report of the Task Force on Archiving of Digital Information," was authored by an Archiving of Digital Information task force of over 20 experts and is considered a seminal report that gives a broad overview of the landscape, concerns, and recommendations for those looking to approach digital preservation at their institutions. ${ }^{13}$ Another foundational text is the "Reference Model for an Open Archival Information System (OAIS)" created by the Consultative Committee for Space Data Systems, and now published as ISO standard $14721 .^{14}$

\footnotetext{
${ }^{1}$ Those interested in emulation may want to explore the work Yale University is doing on "Emulation-as-aService-Infastructure," https://www.softwarepreservationnetwork.org/eaasi/.
} 
While the 5R permissions inherent in OER are liberatory, they also pose challenges from a digital preservation perspective. Preservation planning must start at the beginning of the project lifecycle, with each institution considering the scope of what they want to preserve when faculty start to create OER. Provenance, versioning, ${ }^{15}$ and the fact that OER can be an amalgamation of digital objects and files in multiple formats that are altered over time all present challenges.

\section{Digital Preservation of OER}

Similarly, digital preservation of open educational resources is only addressed a few times in the library literature on OER, almost always as part of a larger discussion about the repositories that host OER. For example, in “Navigating OER: The Library's Role in Bringing OER to Campus," University of San Diego librarians Julia Hess, Alejandra Nann, and Kelly Riddle note that digital preservation "is a significant challenge due to the short lifespan of the repositories in which [OER] are typically housed."16 They cite Norm Friesen's 2009 study of eleven open repositories that had been discontinued, which found that "the average lifetime of these repositories was less than three years." ${ }^{17}$ They conclude that the responsibility for preservation currently falls to creators, who might not have the time or expertise to adequately preserve OER.

Several studies evaluate OER repositories, but their capacity for preservation is often not explicitly mentioned. For example, in 2013 University of London faculty members Javiera Atenas and Leo Havemann analyzed the functionality of 80 OER repositories. ${ }^{18}$ Their assessment notes peer review functionality, metadata standards, Creative Commons license integration, multilingual support, and the availability of source code, but not preservation. However, even when evaluation of preservation practices is not part of the study design, it can come up. One study from researchers Tel Amiel and Tiago Chagas Soares analyzed 50 
repositories. While they did not originally intend to discuss preservation of OER, one-fifth (10) of the repositories in the study had to be eliminated from the analysis because they were defunct. This left the authors to conclude that "[e]ven though we did not have the intention to promote a deeper insight on repositories regarding technical and maintenance issues, it is interesting to note that technical consistency and availability may contribute to a lack of visibility of these repositories and uptake of the resources."19

Studies that focus on how OER programs share content sometimes discuss the longterm availability of OER, which is related to preservation. One from the Centre for Academic Practice and Learning Enhancement (CAPLE) and the Centre for Educational Technology and Interoperability Standards (CETIS) at the University of Strathclyde explored the involvement of libraries within open educational resources (OER) initiatives by surveying over fifty institutions or OER initiatives in the United Kingdom, the United States, Spain, South Africa, India, and Nigeria. While most of the survey respondents for each program described sharing OER through a repository, one third of the respondents shared OER through third-party services (e.g. Youtube, iTunes, Slideshare, Flickr), their learning management system (LMS), or project websites or blogs. When this same survey asked "in which of the following activities are the librarians or the Library involved in your OER initiative and which is their level of responsibility/ commitment?," only 11 respondents (or about one fifth) said the library assisted them with preservation. ${ }^{20}$ This lack of library preservation assistance might provide one explanation for programs utilizing third-party providers like YouTube for storage and access. This is problematic, as Kleymeer, Kleinman, and Hanss rightly note, since open courseware publishing platforms and learning management systems are not designed for long-term preservation. ${ }^{21}$

Finally, a number of publications have explored issues related to long-term access and adaptability of OER, which are closely related but not always explicitly connected to the 
issue of digital preservation. These publications are integral resources for OER creators and introduce several issues that are fundamental to OER preservation, including ideal file formats, software requirements, versioning, and metadata.

For example, John Hilton, David Wiley, Jared Stein, and Aaron Johnson published the ALMS Framework in $2010 .{ }^{22}$ The Framework provides a mechanism for assessing how editable OER actually are, based on the level of technical expertise and the software a user might need to modify it. ALMS stands for Access to editing tools, Level of Expertise required, Meaningfully editable, and Source files. While ALMS does not explicitly mention preservation, its focus on file format constraints and interoperability is an important precursor. Seth Gurell has taken the ALMS Framework a step further by creating a rubric that can be used to assess individual OER and entire OER repositories in order to understand how editable/ adaptable they are. ${ }^{23}$ Librarian Steven Ovadia's 2019 article on the technical constraints users experience when enacting the 5R permissions builds upon the ALMS framework, recommending that creators adopt several open source software practices, including using markdown and distributed version control. ${ }^{24}$ Similarly, the Open Textbook Network's “Modifying an Open Textbook: What You Need to Know" provides an important discussion on the software needed to edit specific file formats, asking creators to think about longevity and downstream use as part of their creation process. ${ }^{25}$

\section{Libraries' Current Approach}

While the literature does not delve into how libraries currently preserve OER, discussion of OER preservation generally centers on using institutional repositories (IRs). For example, in their discussion of the future of OER, University of Michigan librarians Pieter Kleymeer, Molly Kleinman, and Ted Hanss hold that institutional repositories built on DSpace and Fedora are committed to long-term preservation, making them an excellent 
option for sharing and preserving OER. ${ }^{26}$ Librarian Christine Ferguson's examination of three library OER incentive programs found that this emphasis on the IR was a trend across institutions. ${ }^{27}$ Ferguson finds that several more libraries use their IR as a central OER preservation strategy, including the University of Kansas, Orange Grove, Cleveland State University, Grand Valley State University, California State University San Marcos, and the University of Minnesota.

Libraries' explicit dependence on using institutional repositories to preserve OER raises important questions. How many IRs have preservation workflows "baked in," and can support the preservation of a range of born-digital objects, including wikis and videos? Does the reliance on institutional repositories leave creators with less funding and no IR out of the picture, including community college libraries? If an institutional repository is not available, can creators assume that community repositories like OER Commons and MERLOT will preserve their OER?

\section{Digital Preservation of eBooks \& Other Digital Objects}

While guidance on the digital preservation of OER is underdeveloped, practitioners can consult literature on preserving other complex digital objects, including enhanced eBooks and monographs, research data, Geographic Information Systems (GIS), ${ }^{28}$ digital humanities and digital scholarship projects, ${ }^{29}$ web pages ${ }^{30}$ and even gaming environments for inspiration.

Literature on preserving enhanced eBooks is particularly relevant. Scholarly publishing expert Charles Watkinson defines enhanced eBooks as any "eBook which may include digital affordances such as time-based multimedia (audio, video), annotations, interactive timelines, or maps." ${ }^{31}$ Enhanced eBook projects are already utilizing preservation networks in a way that OER creators could emulate. As an example, the book-publishing tool Fulcrum is planning to deposit enhanced media in partnership with distributed preservation 
networks like APTrust. ${ }^{32}$ However, this trend is new and still developing, as preservation organizations like Portico and LOCKSS do not yet have the capacity to accommodate many enhancements. Additionally, literature like the Digital Preservation Coalition (DPC) Technology Watch Report on preserving eBooks ${ }^{33}$ present models for sustainably funding the preservation of eBooks that could inform a conversation about funding OER preservation: a Collective Model (HathiTrust), a Subscription Service (Portico and CLOCKSS), and government support/ grant funding.

OER practitioners could also look to the preservation of digital humanities projects for inspiration. In a Library of Congress blog post entitled "Digital Humanities and Digital Preservation," digital preservation expert Leslie Johnston describes two schools of thought for preserving digital humanities projects: "Preserve the content and the look and feel exactly as they were implemented, [which is] often close to impossible" or "[p]reserve the content but forgo the look and feel, [which is] often extremely unpopular." ${ }^{34}$ Johnston concludes that preservation planning should start at the beginning of a project, open content format standards must be considered, and all decisions should be documented, including "the rights and provenance of all content and metadata." 35 As with the discourse on eBook preservation, conversations about digital humanities and digital scholarship preservation are still emerging. While these areas of the literature are informative and inspirational, specific guidance on preserving open educational resources is still needed.

\section{Methodology}

The following research design was created with two goals: to understand how current OER creation incentive programs are preserving content, if at all, and to name and explore barriers to and considerations for preserving OER. 


\section{Analysis of Current Preservation Practices}

In order to better understand how library programs in the United States and Canada are requiring or encouraging OER creators they incentivize to preserve OER, the authors conducted an analysis of OER creation program requirements. This process utilized data from the Scholarly Publishing and Resource Coalition's (SPARC) Connect OER Report. ${ }^{36}$ Data from the 2016-2017 report "encompass 65 SPARC member libraries spanning 31 U.S. states and five Canadian provinces." ${ }^{37}$ While 65 institutions provided profiles, only 27 submitted OER grant program information. Those 27 programs could select primary and secondary focuses of their programs from this list: adaptation, adoption, awareness, curation, pedagogy, publication, review, and research. The authors further limited the analysis to 20 programs by selecting those that chose curation or publication as a primary or secondary strategy of their program, as creation was core to the analysis.

Of those 20 programs, programs where creation or publication of OER was not explicitly mentioned on the grant program website were omitted. Programs where the link to the program website provided through the SPARC survey was broken were also omitted. This limited our analysis to 14 programs. The authors navigated to each of the 14 program's public grant application sites and assessed the publicly available information by answering a set of questions about digital preservation of content:

- Is “digital preservation" or "preservation" explicitly mentioned?

- Is a digital preservation librarian mentioned, or listed on any related OER program committee list or contact information?

- Are there preservation or digital preservation requirements on the OER program evaluation rubric or application?

- Is "sustainability" mentioned or listed on the OER program evaluation rubric or application? 
- Is there a requirement to share the final OER in an institutional repository?

- Is there a requirement to share the final OER in another repository outside of the program's institution?

The authors acknowledge that some of the information sought, as it relates to digital preservation and OER grant program specifics, may not be listed on the public website for the OER program, but rather within internal documentation. This could lead to inaccuracies in our findings. However, it is important to note that if this information is limited only to internal documentation, it is not public to faculty applying for the incentive, making these requirements invisible at the outset.

None of the programs evaluated explicitly mention preservation or digital preservation on their public OER program websites, applications, or evaluation rubrics. Three programs, Kansas State University, University of Kansas, and University of Minnesota, mention "sustainability," though not necessarily in a preservation sense. In using the term "sustainability," the authors assume these programs are referring to whether or not the OER will be utilized in a class that will regularly be held and taught every academic year.

About a third of programs (6) explicitly require creators to deposit the final OER in either an institutional or outside repository in order to receive funding. This could imply that these OER incentive programs believe that repositories suffice as preservation. Table 1 explores each program's requirements in more detail. Details about each program are accurate as of January 2019 but may change over time.

\begin{tabular}{|l|l|l|l|}
\hline Institution & $\begin{array}{l}\text { Mention of Digital } \\
\text { Preservation? }\end{array}$ & $\begin{array}{l}\text { Licensing } \\
\text { Requirement }\end{array}$ & $\begin{array}{l}\text { Repository } \\
\text { Submission } \\
\text { Requirement }\end{array}$ \\
\hline $\begin{array}{l}\text { University of } \\
\text { Arkansas }\end{array}$ & No & $\begin{array}{l}\text { Yes, must be } \\
\text { published with an } \\
\text { open creative } \\
\text { commons license }\end{array}$ & $\begin{array}{l}\text { Yes, must be made } \\
\text { available on an } \\
\text { accessible open } \\
\text { platform }\end{array}$ \\
\hline
\end{tabular}




\begin{tabular}{|c|c|c|c|}
\hline Clemson University & No & $\begin{array}{l}\text { Not required, but } \\
\text { preference will be } \\
\text { given to proposals } \\
\text { using materials } \\
\text { licensed CC-BY }\end{array}$ & Not stated \\
\hline $\begin{array}{l}\text { Fort Hays State } \\
\text { University }\end{array}$ & No & $\begin{array}{l}\text { Yes, program does } \\
\text { not allow the } \\
\text { creation or } \\
\text { adaptation of } \\
\text { textbooks without } \\
\text { the accompaniment } \\
\text { of a Creative } \\
\text { Commons license }\end{array}$ & $\begin{array}{l}\text { Yes, must be } \\
\text { uploaded to the } \\
\text { FHSU Scholars } \\
\text { Repository }\end{array}$ \\
\hline $\begin{array}{l}\text { Kansas State } \\
\text { University }\end{array}$ & $\begin{array}{l}\text { No, but } \\
\text { "sustainability" } \\
\text { mentioned in } \\
\text { evaluation criteria }\end{array}$ & $\begin{array}{l}\text { Not required, but it } \\
\text { is discussed in the } \\
\text { evaluation rubric: } \\
\text { http://www.lib.k- } \\
\text { state.edu/textbook- } \\
\text { selection-criteria }\end{array}$ & Not stated \\
\hline University of Kansas & $\begin{array}{l}\text { No, but } \\
\text { "sustainability" } \\
\text { mentioned in } \\
\text { evaluation criteria }\end{array}$ & Not stated & Not stated \\
\hline $\begin{array}{l}\text { North Carolina State } \\
\text { University }\end{array}$ & No & Not stated & Not stated \\
\hline $\begin{array}{l}\text { University of } \\
\text { Oklahoma }\end{array}$ & No & $\begin{array}{l}\text { Yes, grantees in the } \\
\text { "Creation" category } \\
\text { will be expected to } \\
\text { apply a Creative } \\
\text { Commons License } \\
\text { (of author's choice) } \\
\text { to the OER they } \\
\text { create }\end{array}$ & $\begin{array}{l}\text { Yes, grantees in the } \\
\text { "Creation" category } \\
\text { will be expected to } \\
\text { upload their OER to } \\
\text { OU's institutional } \\
\text { repository SHARE } \\
\text { OK in exchange for } \\
\text { grant funding }\end{array}$ \\
\hline $\begin{array}{l}\text { Portland State } \\
\text { University }\end{array}$ & No & Not stated & Not stated \\
\hline $\begin{array}{l}\text { Simon Fraser } \\
\text { University }\end{array}$ & No & $\begin{array}{l}\text { Yes, agreement that } \\
\text { the end product will } \\
\text { be openly licensed } \\
\text { (e.g., using Creative } \\
\text { Commons licenses) }\end{array}$ & $\begin{array}{l}\text { Yes, must be } \\
\text { uploaded to Summit, } \\
\text { SFU's institutional } \\
\text { repository }\end{array}$ \\
\hline Temple University & No & Not stated & Not stated \\
\hline University of & No, but & Yes, participants will & Not stated \\
\hline
\end{tabular}




\begin{tabular}{|c|c|c|c|}
\hline Minnesota & $\begin{array}{l}\text { "sustainability" } \\
\text { mentioned in } \\
\text { evaluation criteria }\end{array}$ & $\begin{array}{l}\text { be asked to license } \\
\text { any newly created } \\
\text { materials (CC-BY or } \\
\text { similar open license) }\end{array}$ & \\
\hline $\begin{array}{l}\text { Utah State } \\
\text { University }\end{array}$ & No & $\begin{array}{l}\text { Yes, applicants must } \\
\text { facilitate the } \\
\text { distribution of the } \\
\text { OER via an OER- } \\
\text { compatible Creative } \\
\text { Commons license }\end{array}$ & $\begin{array}{l}\text { Yes, must be } \\
\text { uploaded into USU's } \\
\text { Digital Common }\end{array}$ \\
\hline Virginia Tech & No & $\begin{array}{l}\text { Yes, requires OER } \\
\text { produced through the } \\
\text { grant program to be } \\
\text { licensed CC-BY }\end{array}$ & $\begin{array}{l}\text { Grant letter of } \\
\text { agreement requires } \\
\text { that the OER output } \\
\text { is publicly shared via } \\
\text { a public portal }\end{array}$ \\
\hline $\begin{array}{l}\text { Washington State } \\
\text { University }\end{array}$ & No & $\begin{array}{l}\text { Yes, all OER } \\
\text { creation or } \\
\text { adaptation must be } \\
\text { accompanied by a } \\
\text { Creative Commons } \\
\text { license }\end{array}$ & Not stated \\
\hline
\end{tabular}

Table 1: Preservation Requirements of Library OER Creation Incentive Programs

There are many reasons why an institution may not consider digital preservation of OER. First, digital preservation requires resources, staff, and expertise, all of which may be out of reach for a particular institution. Perhaps current library staff do not know about how digital preservation works and are not sure about how to approach preserving OER. It could be that digital preservation simply is not discussed or seen as necessary. Perhaps an institution has determined that OER on their campuses are not worth preserving for the long term. Lastly, an OER team or librarian may not consider consulting with preservation experts on their campus as they develop their program, as the focus is often on outreach and cost savings. 


\section{Interviews}

After discovering that digital preservation of OER is a gap both in practice and in the literature, the authors opted to interview experts in digital preservation, metadata, repositories, and OER in order to better understand the challenges related to preserving OER. The aim of each interview was to construct a set of practices for preserving OER.

\section{Participants}

Potential interviewees were identified by reviewing publications on relevant topics and through word of mouth. The authors invited ten individuals and four OER repository staff members to be interviewed for this study. Six of the ten invited individuals were willing and able to be interviewed. None of the OER repository staff members were available. Interviewees represented perspectives from university presses, libraries, and consortia projects.

While there are limitations to a small interview pool, the authors intentionally prioritized in-depth conversations with a small number of internationally recognized experts over collecting a large number of more general responses via a survey. In addition to more readily surfacing complexities and nuances, this qualitative approach attempts to make the interviewees' expertise more accessible to all, including OER librarians who are novices in digital preservation. Additional details about interviewees are described in Table 2. The results section refers to interviewees by the specific number assigned below.

\begin{tabular}{|l|l|l|}
\hline Interviewee Number & Expertise & Type of Institution \\
\hline 1 & Digital libraries & $\begin{array}{l}\text { Large public research } \\
\text { university (Canada) }\end{array}$ \\
\hline 2 & Scholarly publishing & $\begin{array}{l}\text { Large public research } \\
\text { university (US) }\end{array}$ \\
\hline
\end{tabular}




\begin{tabular}{|l|l|l|}
\hline 3 & Digital preservation & Library consortium (Canada) \\
\hline 4 & Open education & $\begin{array}{l}\text { Large public research } \\
\text { university (US) }\end{array}$ \\
\hline 5 & Digital preservation & $\begin{array}{l}\text { Large public research } \\
\text { university (US) }\end{array}$ \\
\hline 6 & Digital preservation & $\begin{array}{l}\text { Medium private research } \\
\text { university (US) }\end{array}$ \\
\hline
\end{tabular}

Table 2: Summary of Study Participants

\section{Data Collection \& Instrument}

The authors conducted semi-structured interviews between July and December 2018. Interview questions (available in Appendix A) were given to participants beforehand as part of the consent form participants were required to sign. Interview protocol was approved by both [university names withheld] Institutional Review Boards (IRB).

Interviews were truly semi-structured. While every question on the list (Appendix A) was asked, interviewees were often asked follow-up questions based on their response, area of expertise, or current position. This flexible research design recognizes the value of having the expert lead the interview in order to surface new lines of inquiry not yet considered by the authors. Both authors were present for each interview. Interviews varied in length, ranging from 25 minutes to 50 minutes.

\section{Data Analysis}

Every participant permitted the authors to record their interview. Recordings were auto transcribed and then reviewed and edited by one of the authors for accuracy. Each author reviewed a subset of the transcripts and proposed themes of interest. Authors then reviewed these themes, combining similar concepts and adding additional themes as needed, in order to create a final codebook before reviewing all transcripts. Both authors coded each of the six 
interviews individually, tagging relevant text with specific codes. Authors then analyzed interview transcripts for each code individually.

\section{Results}

The following sections summarize key themes multiple interviewees discussed. While themes are presented as distinct topics within this section, many of the themes overlap or complement each other and, as such, should be considered in tandem. Themes move from more straightforward suggestions (i.e. collaborating with archivists) to more complicated issues (i.e. forming consortia groups and implementing standardized metadata practices). The end of each section summarizes key recommendations.

\section{Inspiring Cross-Pollination}

Many of the interviewees emphasized that digital preservation is not something that is done alone. Interviewee 6 noted that digital preservation librarians have to be intentional about not creating fiefdoms and instead have to focus on finding allies in order to avoid replication of work. This speaks to the collaborative approach inherent in digital preservation work. Conversely, Interviewee 4 lamented the loneliness of being "the OER person" at their library. They mentioned not being introduced to other people in the library who could further their OER work, namely digital preservation and archives experts. In what ways can institutions help spark cross-departmental collaborations if OER is a priority? How can management ensure that people meet one another and share expertise? This is a special concern within "new" types of library positions (such as OER Librarian positions), where an individual may be the first person in the position and is unsure where partnerships and allies are within the library. Interviewee 4 suggested, "Another way that might be really helpful for 
people who are just getting started... is if there were best practices of people you should identify as collaborators ... nobody is making [those guidelines] yet." Such a list could help librarians tasked with OER work jumpstart conversations with key partners.

Several interviewees proposed that this list include digital preservation librarians, archivists, and record managers. This was in part because of the importance they placed on archival appraisal when considering preservation of OER. Appraisal in archives is a decisionmaking process whereby archivists consider which objects to keep for preservation, including the expected usefulness for their user community, the anticipated length of preservation or retention schedule, the object's condition and costs to maintain, its authenticity, and its overall intrinsic value. Consulting with an archivist to establish parameters and understand what is and is not possible when preserving OER at one's institution is essential for responsible and realistic stewardship. Going forward, this helps establish a foundation for making decisions about which OER to keep and provides guidelines for discussions about preservation with OER creators.

Interviewee 6 conveyed the importance of this process by noting that "Every time you decide to preserve something it's got a long term commitment associated with it, you can't take a year off [with preservation], you've got to keep going... There's no category I know of where we keep everything always. And that's records management." This interviewee applied this statement to OER specifically, stating that if there were 150 courses using OER at a given campus, appraisal might involve preserving a sample across courses or using event-based appraisal which prioritizes particular OER "because [they were] the first, the best, award winning, [or] by the first woman faculty person.” Interviewee 5 further elaborated on archival appraisal by encouraging those interested in OER to consider periodically evaluate challenges to preservation and resources every few years. This iterative approach to appraisal might mean that materials are deaccessioned. In short, since we don't know 
"whether these objects will be difficult to preserve or not," gathering download data and information on new preservation challenges every few years could be invaluable. The recommendation to collaborate with record managers and archivists that have vast experience in selecting which objects to preserve and to make policies flexible will be integral for librarians interested in sustainable preservation.

Those interested in inspiring cross-pollination between OER experts and digital preservation/ archives experts could look to professional development opportunities. Interviewee 2 encouraged OER and digital preservation experts to consider co-authoring publications and co-presenting at conferences in order for both audiences to increase exposure. Interviewee 6 wondered how different groups such as the Association of Research Libraries (ARL), the Association of College and Research Libraries (ACRL), the American Library Association (ALA), and the Digital Library Federation (DLF), among others, could bring these experts together. This could take the form of publishing a white paper on OER and digital preservation or hosting webinars and conversations around this topic.

\section{Recommendations}

- Create a list of key stakeholders OER experts should approach when creating incentive programs

- On a national level, encourage organizations like ARL, ACRL, and DLF to create spaces for cross-pollination

- In partnership with archivists, establish an appraisal policy for OER that considers the local user community, preservation challenges, and value to the broader teaching and learning community 


\section{The Need for Management and Owning Our Expertise}

The previous section makes clear that the digital preservation of OER is a management issue. Preserving OER involves utilizing expertise within the library, making decisions early on about preservation policy, and determining what should be preserved and maintained, all of which requires communication and coordination across multiple units. A couple of the interviewees encouraged libraries to take a "high-level view" of their organization and its priorities when considering preserving OER, and strategically plan for overlap across units. Interviewee 1 even proclaimed that digital preservation of OER is not a technical issue or an issue of faculty interest, but instead a management issue. This is partly because taking on digital preservation of OER systematically requires that time, energy, and resources be diverted from other activities in order to make efforts sustainable.

In addition to management making the preservation of OER a priority, preservation will require librarians to own their expertise and intentionally incorporate this expertise into grant programs. Libraries have established precedent for requiring specific file formats or other submission parameters for researchers when they upload electronic theses, dissertations, and other works into institutional or data repositories. OER grant and award programs interested in preserving their completed OER projects could consider outlining required OER file formats or creation parameters in the submission requirements in order for awardees to participate and receive funding. Academic librarian and technology expert Steven Ovadia's guidance on using Markdown or text files might be useful in this endeavour. ${ }^{38}$

Interviewee 1 highlighted this idea of owning one's expertise well: “I think we just need to start seeing all of these digital pieces as our responsibility... [T]his is literally our area of expertise, and we would never go to [instructors] and assume to tell them how to teach their history class. I don't know why we acquiesce when they're like, 'no, I want to create [a digital object, project, or OER] in this format only and you'll have to figure it out."' 
Interviewee 6 echoed this sentiment, stating that "Managing well doesn't mean some faculty member figuring out what's good enough. It means partnering with them to make sure that it's easy for them to do what they need to do."

In short, when librarians hesitate to require faculty to plan for preservation, either through identifying acceptable file formats or by requiring that a librarian is embedded in the creation process, we do a disservice to our professional expertise and to the longevity of the OER created. Before figuring out the details of what OER libraries will preserve or how, administrators must decide that preservation of OER is important and librarians must recognize that their professional expertise can inform the creation process.

\section{Recommendations}

- Intentionally and structurally bring disparate groups together to make OER preservation possible

- Decide what other services/ resources will be cut in order to make preservation endeavours realistic and sustainable

- Own the preservation expertise librarians have by requiring faculty to create OER with tools and file formats that have been evaluated beforehand, ideally articulating this in policy

\section{Consortia Strategies}

Several interviewees discussed the real financial barriers to doing quality digital preservation. As a result, consortia strategies for funding digital preservation of OER was continually mentioned. Interviewees generally felt that consortia models enable the community to share the burden of cost, ultimately empowering institutions that have less resources to preserve their OER. 
Interviewee 3 noted that "there's no need to reinvent the wheel" as a variety of consortia digital preservation networks already exist. They noted that "Many institutions have subscriptions to those [networks]" holding that they did not see why "a library with a subscription to Portico or CLOCKSS couldn't extend some of that benefit to a smaller situation with which they have an agreement." Consortia preservation providers mentioned by interviewees included Lyrasis, Portico, LOCKSS, and CLOCKSS.

However, using existing preservation networks might be more challenging than simply formalizing partnerships. Another interviewee questioned the technical infrastructure that would actually be needed to make pushing content to a consortia network feasible. They explicitly mentioned building application programming interfaces (APIs) into OER tools in order to send content to entities like CLOCKSS. Other questions around using consortia preservation networks for OER preservation still exist. For example, Interviewee 3 mentioned the challenge of shared values: how might we, as a community, agree on what level of preservation to offer? What are the challenges inherent in sharing resources and shifting financial responsibility to well-resourced institutions?

\section{Recommendations}

- Build upon existing consortia agreements that preserve digital content so that OER are included

- Facilitate community conversation about how to preserve OER consortially

\section{Managing Parts \& Versions}

Interviewees clearly articulated that adequately capturing the versions (defined here as iterations of a particular OER) and parts (defined here as portions, chapters, or sections) of each OER is an essential and inherent element of preservation. The concern with capturing 
provenance information, adaptations, and even interactions with the OER is closely tied to the $5 \mathrm{R}$ permissions and users' ability to enact them fully. Interviewee 1 even posited that the ability to manage parts and versions will be key to libraries furthering openly broadly: "Showing the currency of the work is always going to be important and I think will become even more important... [to show that] your work is actually being used. So, I think it's being able to show the different versions and to store them in a way... kind of like Time Machine backup on your laptop, like how can we pick a time and a place and see what that chapter was used for?" One way librarians could approach this kind of versioning is by assigning a unique digital object identifier (DOI) to each version of an OER, or even each part of the OER, in order to track changes over time. This would also enable more robust citation of the original version. Another option is creating a distributed version control tool for OER, similar to Git, as Ovadia recommends. ${ }^{39}$ This approach would allow OER creators to track iterations of their OER while maintaining a master copy for their own use.

In addition to thinking through the pieces of OER, a question that many interviewees grappled with is “when is an OER 'done enough' to preserve?" The beauty of OER is that they are never complete as the license empowers anyone to revise and update them whenever they would like. While there was not a consensus on how to handle parts and versioning, interviewees generally felt that saving changes to individual parts of an OER often, along with recording the relationships between each of these parts through detailed metadata, were useful first steps. They also recommended that OER preservation policies define how significant changes have to be for the OER to be considered a new object.

Interviewee 2 noted that versioning is more complex than just tracking content and encouraged those interested in preservation to take into account the "layers of interaction" a particular OER embodies. They noted three layers: the base content, the dynamic media, and the network layer. They defined the network layer as interactions readers and students have 
with the OER, which might include annotations. They held that using this model to evaluate which layer(s) need to be preserved will be integral. It is important to note that this kind of preservation brings up important privacy questions and requires a larger discussion about how to attain students' consent.

\section{Recommendations}

- Explore assigning DOIs to whole OER or parts of OER to track versioning and encourage permanence

- Explore using distributed version control mechanisms as described by Steven Ovadia

- Decide when an OER is deemed a new object and articulate this in preservation policies

- Record relationships between parts of an OER with robust metadata

\section{Metadata}

Nearly all of the interview participants emphasized how integral metadata is to preservation, noting that even if we are able to create tools and workflows that effectively track versions, assigning metadata that adequately describes how an OER was revised and remixed is key to any preservation strategy. Interviewee 2 explained that metadata is mechanism for "rich, deep, complex storytelling... to the future" and that even if the OER is lost, the knowledge "about what was there would remain if the storytelling was done effectively." This interviewee suggested that preservation and metadata policies at least include chain of custody information or background on how the OER was acquired. For example, the PREMIS (Preservation Metadata: Implementation Strategies) schema is widely recognized as the standard for documenting preservation metadata. It allows for the recording of digital provenance and specific preservation actions undertaken by institutions. The data 
model allows actions to be related to specific objects as well as the responsible parties (both human and computer).

Still, figuring out the logistics of describing OER and collecting this metadata can be challenging. Interviewee 3 held that using existing metadata schema or an XML file might suffice, mentioning the "is part of" element of Dublin Core as an example. While this might be easy to implement if a library runs the institutional repository where faculty submit OER, it is more challenging if faculty share their OER in a community repository. In Atenas and Havemannon's analysis of repositories, they found that "only $38.75 \%$ of the repositories include the use of standardised metadata such as either Dublin Core or Learning Object Metadata which.... can be transferred across repositories." ${ }^{40}$ In addition to advocating for using specific metadata schema in these repositories, OER practitioners should push for optional metadata fields that add context that is useful for both educators and for preservation purposes. These standardized fields might include learning outcomes, accessibility information, mobile compatibility, technical requirements, geographic coverage, temporal coverage, source information, clearly defined rights statements, and date uploaded.

One potential solution for including more detailed metadata is creating a "code book" that provides additional context. Interviewee 1 noted that they would like to see "a workflow attached to every learning object [about] where the source information came from, who supported it, [and] how the library did what they did." This interviewee further explained that the code book could describe pieces of the learning object, who was involved, and which funding source(s) was used. They added, "I think that's where you surface all the labor that goes into these [OER] as well... the labor just disappears because they assume that it's a tool that does all the work, not all the people poking at the tool.” There is precedent for creating such a "code book" in other open spaces. For example, it is fairly common practice to submit a ReadMe when sharing open data so that users of the dataset know how the data was 
collected, cleaned, and analyzed. Those interested in preserving OER could easily mimic this practice, providing an explanatory ReadMe when OER are deposited in institutional or community repositories.

\section{Recommendations}

- Consider requiring a code book or ReadMe when OER are deposited to encourage additional context around labor, funding, tool(s) used, and decision making

- Use and enhance existing metadata schema in institutional and community repositories, possibly exploring PREMIS and Learning Object Metadata (LOM)

\section{Repositories \& Preservation of OER}

Interviewees expressed the disconnect between institutional repositories and preservation strategies. For example, interviewee 5 said, "a lot of [institutional repositories] end up being a sort of dumping ground. There's not necessarily a guarantee of the long-term accessibility of that content. I think that's better than nothing, but just by virtue of it being an IR, it doesn't necessarily guarantee what we mean by preservation. It could, but it depends on the policies of the IR and how that IR is staffed and operated." Interviewee 3 explained a common difference between IR and preservation workflows: "[IRs] do access... If there are preservation workflows, they tend to be separate from the IRs. You might deposit something that could get preserved using another workflow."

Interviewee 5 suggested "going back to the basics" as a strategy for untangling IRs and preservation. They emphasized secure redundant storage, fixity checking, and using trusted repositories whenever possible. Fixity checking is way to document the integrity of content and then periodically recalculate the checksums of digital objects to compare against the stored values. Essentially, this process is checking to make sure that none of the digital 
information associated with the object has changed over time. Interviewee 5 also felt that institutional repositories must have explicit preservation approaches baked into their systems in order to claim to preserve OER.

Interviewees also discussed community OER repositories, or repositories open to all depositors (regardless of institutional affiliation) and devoted to learning objects and/or OER. The interviews surfaced that there is a lack of transparency about who "owns" community OER repository infrastructure. There was sometimes an assumption that they are supported by the institutions they are housed within or even by funders like the Hewlett Foundation. However, funding sources and sustainability plans should be explicit and clear to both those searching for and those creating OER for deposit.

\section{Recommendations}

- Be clear with users about the preservation capacity of your institutional repository

- Demand that community repositories explicitly state their preservation and sustainability plans before recommending them to depositors

- Compile deposit requirements (or best practices) for preservation, including file format

\section{Discussion}

There are several important steps librarians can take to operationalize the themes discussed above, both in their day-to-day work and in their OER incentive program requirements. The following section synthesizes interviewees' ideas so that they can be operationalized by those working with OER creators. It is important to note that these are ideas that will not make sense in every institutional context. There are several barriers to successfully implementing these recommendations, most obviously that OER work is almost 
never a librarian's sole responsibility. Other barriers include negotiating with funding partners (i.e. the Center for Teaching and Learning, IT, etc.) on grant requirements and structuring funding so that creators comply.

\section{Create Policies to Outline Creator/ Library Responsibilities}

Communicating institutional practices and priorities clearly before the OER creation process begins in a formal policy is ideal. This level of transparency can help creators understand expectations and benefits in the planning stages of their project instead of in the middle of the OER creation process. A policy might define the object of preservation (i.e. the OER itself or interactions with the content), include specific preservation actions the library can commit to, and make explicit the appraisal criteria the library will use to select OER to preserve as well as conventions for version control, including how often the library will preserve new versions. Policies should clearly outline the expectations of creators in regard to file format, tools used, and sharing requirements. If creators are given a financial stipend from the library for creating the OER, policies might need to formalized in a memorandum of understanding (MOU). The process of crafting policies and MOUs can be a reflective exercise for deciding which of the following recommendations an institution prioritizes.

\section{Review Periodically}

Librarians involved in OER work should consider reviewing what kinds of OER are being created and OER already created and shared (possibly within the IR) at their institution. The review process will inherently shape the creation of standards and guide collaboration with digital preservation experts. For example, we cannot outline which tools do not allow exporting or harvesting until we know about them. We cannot and should not preserve 
everything, but auditing can inform how we might strategically assess or preserve a sample of the OER created at our institutions.

\section{Include Digital Preservation Experts on Incentive Committees}

It is clear that OER creation working groups or committees should not only include librarians focused on instruction or OER outreach. Records managers, archivists, and digital preservation librarians should be included in order to further conversations about preservation. Including them in planning could mean that metadata, format, and repository functionality is considered from the outset.

\section{Require OER to be ADA-Compliant}

Interviewee 1 noted that if OER are accessible then they are generally easier to preserve. Requiring ADA compliance from stipend recipients (and encouraging it whenever the library is doing outreach) can be a useful strategy for ensuring that creators are designing accessible OER from the beginning instead of trying to make existing OER accessible after the fact. Interviewee 1 noted that this strategy would lead to the creation of "uber usable learning objects," both because of the license they are shared under but also because they are “technologically... as friendly as possible to as many systems as possible." If libraries are committed to accessibility, this requirement is integral.

\section{Improve Metadata}

One way to improve the metadata shared alongside an OER is to attach a ReadMe file. This would give future readers and educators additional context while also documenting the labor that goes into the creation of any OER. Potential ReadMe items could include funding body, creators, license shared under, preservation decisions made, source URLs and 
licenses, and even educational context (learning objectives, syllabus, curriculum sequencing, etc.). Librarians should also advocate for using established metadata schema like Learning Object Metadata (LOM) when creating guidelines and requirements for instructors.

\section{Next Steps}

Interviewees identified several areas where future research is needed. These ideas were outside the scope of this article but are important for moving the conversation about OER preservation forward.

Interviewee 5 suggested that the first step in preserving OER at scale would be to collect a corpus of OER and analyze preservation needs, common file formats, current metadata standards used, tools used to create, and any risks for access. The interviewee noted that until this kind of analysis is done, we can only speculate on what kinds of difficulties OER librarians would encounter. This approach would also allow the community to identify common models for preservation and articulate how they might be different for specific kinds of OER. For example, a highly interactive OER with 3D objects intended for an-upper level course would probably require different preservation planning than a static Biology 101 textbook.

In line with the theme of sharing resources across institutions, interviewees recommended that the OER community investigate drafting a shared business case for convincing grant funding institutions and local administration to consider OER preservation as a strategic priority. Other community resources could include an assessment of OER creation tools for preservation needs, draft OER preservation workflows, and information on how other areas of librarianship have approached the preservation of complex content. Further study is also needed to gauge feasibility and interest in this topic. 


\section{Limitations}

This study was designed to be exploratory. As such, it has several limitations. The assessment of what libraries are currently doing to preserve OER created as part of an incentive program is limited to public information shared on a small subset (14) of OER creation programs' websites. Data was pulled from SPARC's OER Connect dataset, also limiting the type of institutions evaluated. Future studies interested in assessing what libraries are actually doing to preserve OER could interview OER creation programs firsthand to map out their process in more detail. This kind of investigation would help the OER community understand current practices, not just best practices.

One obvious limitation of this study is the small number (six) of interviews conducted. Interviews were generally skewed toward a particular type of institution and perspective, namely the perspective of librarians working in well-funded research libraries. This approach misses the important perspective of technical staff, who potentially have greater expertise in the day-to-day preservation practices at a given institution. The authors also reached out to staff at key OER repositories (4) but they were unable to discuss their preservation policies and infrastructure. Preservation information is generally difficult to find but foundational to creators looking for a space to share their work. OER repositories should clearly state their funding structures, sustainability plan, preservation policy, and preservation infrastructure on their public website. This information should also be shared at conferences and discussed in the literature in order to raise awareness.

\section{Conclusion}

Academic libraries of all sizes and missions continue to express an interest in furthering the adoption and creation of open educational resources at their institution as 
awareness of OER grows. This work is more complex than raising faculty awareness or even incentivizing faculty exploration of OER. Librarian Steven Ovadia holds that "a work's license can decree the work reusable, but if there is no software to open it, the work is not actually reusable in practice." ${ }^{41}$ This is an important reminder for librarians collaborating with instructors to make and adapt OER. Librarians have a responsibility to thoughtfully audit, select, describe, and preserve OER that hold significant value for the teaching and learning missions of our institutions. When we overlook preserving OER, we miss an opportunity to help users realize the first and arguably most essential of Wiley's 5R permissions: retain. In addition to making content available, preserving OER provides an important opportunity to collaborate with colleagues whose expertise can enhance our own, showcase the breadth of expertise the library offers in order to more holistically support users, and extend the reach of open education.

[acknowledgments withheld] 


\section{Appendix A: Interview Questions for Digital Preservation and Metadata Experts}

- What context do you work in?

- What would consider the 2-3 best practices for preserving born-digital learning objects, including videos, textbooks, interactive materials?

- Open Educational Resources or OER are defined as learning objects shared under an intellectual property license that allows others to retain, revise, reuse. What digital preservation advice would you give librarians working with faculty to create OER?

- What recommendations for doing digital preservation/ incorporating it into current OER program with little to no funding?

- Why might OER offer a unique preservation issue, especially in regards to versioning issues with re-mixing?

- One of the issues we see with use and revision of OER is proprietary and obsolete file formats. What recommendations, if any, would you make to prevent or ameliorate this issue?

- In your professional opinion, how might libraries encourage cross-pollination between OER experts and digital preservation experts?

- Do you have any other thoughts on digital preservation and OER that we didn't cover? 


\section{Notes}

${ }^{1}$ David Wiley, "The Access Compromise and the 5th R," Iterating Toward Openness, March 5, 2014, https://opencontent.org/blog/archives/3221

${ }^{2}$ CollegeBoard, "Quick Guide: College Costs,” 2017, https://bigfuture.collegeboard.org/payfor-college/college-costs/quick-guide-college-costs

${ }^{3}$ Andrew Feldstein, Mirta Martin, Amy Hudson, Kiara Warren, John Hilton, and David Wiley. "Open Textbooks and Increased Student Access and Outcomes. European Journal of Open, Distance and E-Learning, 2 (2017): 1, http://www.eurodl.org/index.php?p=archives\&year=2012\&halfyear=2\&article=533

${ }^{4}$ Quill West, Amy Hofer, and Dale Coleman, Librarians as Open Education Leaders: Responsibilities and Possibilities: 3, https://drive.google.com/open?id=1NzjguflBLny_dXErmSdgDP0_LIghHZ7M

${ }^{5}$ Christine Ferguson, "Open Educational Resources and Institutional Repositories," Serials Review, 43, 1 (2017), doi:10.1080/00987913.2016.1274219; Anita Walz, Kristi Jensen, and Joseph Salem, SPEC Kit 351: Affordable Course Content and Open Educational Resources (Washington, DC: Association of Research Libraries, 2016); Joseph Salem, “Open Pathways to Student Success: Academic Library Partnerships for Open Educational Resource and Affordable Course Content Creation and Adoption. The Journal of Academic Librarianship, 43, 1 (2016): 34-38, doi: 10.1016/j.acalib.2016.10.003; Ethan Senack, "Open Textbooks: The Billion Dollar Solution, The Student PIRGs, 2015, https://studentpirgs.org/reports/sp/opentextbooks-billion-dollar-solution; Anita Walz, "Open and Editable: Exploring Library Engagement in Open Educational Resource Adoption, Adaption and Authoring," Virginia Libraries, 61,1, (2015); Karen Okamoto, "Making Higher Education More Affordable, One Course Reading at a Time: Academic Libraries as Key Advocates for Open Access Textbooks and Educational Resources," Public Services Quarterly, 9, 4 (2013): 267-283, doi:10.1080/15228959.2013.842397.

${ }^{6}$ Okamoto, "Making Higher Education."

${ }^{7}$ Wiley, "The Access Compromise."

${ }^{8}$ Howard Besser, "Digital Longevity," in Handbook for Digital Projects: A Management Tool for Preservation and Access ed. Maxine Sitts (Andover, MA: Northeast Document Conservation Center, 2000). https://www.nedcc.org/assets/media/documents/dman.pdf ${ }^{9} \mathrm{~K} \mid \mathrm{N}$ Consultants, “A Preservation Primer,” 2019, http://knconsultants.org/a-preservationprimer/

${ }^{10}$ Jasmine Mulliken, "3 Approaches to the Preservation of Interactive Scholarly Works," supDigital, August 22, 2018, http://blog.supdigital.org/3-approaches-to-the-preservation-ofinteractive-scholarly-works/

${ }^{11}$ Digital Preservation Coalition, "Digital Preservation Handbook," 2015, https://www.dpconline.org/handbook

${ }^{12}$ Maxine Sitts, Handbook for Digital Projects: A Management Tool for Preservation and Access (Andover, MA: Northeast Document Conservation Center, 2000), https://www.nedcc.org/assets/media/documents/dman.pdf

${ }^{13}$ Donald Waters and John Garrett, "Preserving Digital Information: Report of the Task Force on Archiving of Digital Information," 1996, https://eric.ed.gov/?id=ED395602 
${ }^{14}$ Brian Lavoie, "The Open Archival Information System (OAIS) Reference Model:

Introductory Guide," 2014, https://www.dpconline.org/docs/technology-watch-reports/1359dpctw14-02/file

${ }^{15}$ Chris Aldrich, "The Sixth 'R' of Open Educational Resources," Musings of a Modern Day Cyberneticist, August 30, 2018, https://boffosocko.com/2018/08/30/the-sixth-r-of-openeducational-resources-oer/

${ }^{16}$ Julia Hess, Alejandra Nann, \& Kelly Riddle, "Navigating OER: The Library's Role in Bringing OER to Campus," The Serials Librarian, 70, 1-4, (2016): 130.

${ }^{17}$ Ibid, 130.

${ }^{18}$ Javiera Atenas \& Leo Havemann, "Quality Assurance in the Open: An Evaluation of OER Repositories," The International Journal for Innovation and Quality in Learning, 2 (2013): 22-34.

${ }^{19}$ Tel Amiel and Tiago Chagas Soares, "Identifying Tensions in the Use of Open Licenses in OER Repositories," International Review of Research in Open and Distributed Learning, 17, 3 (2016): 37, http://www.irrodl.org/index.php/irrodl/article/view/2426/3688

${ }^{20}$ Gema Bueno-de-la-Fuente, John Robertson, \& Stuart Boon. "The Roles of Libraries and Information Professionals in Open Educational Resources (OER) Initiatives," JiSC Centre for Educational Technology and Interoperability Standards (CETIS), 2012,

http://digital.library.wisc.edu/1793/63306

${ }^{21}$ Pieter Kleymeer, Molly Kleinman, and Ted Hanss, "Reaching the Heart of the University:

Libraries and the Future of OER" (Paper presentation, Open Education Conference,

Barcelona, Spain, November 2010).

${ }^{22}$ John Hilton, David Wiley, Jared Stein, and Aaron Johnson, "The Four R's of Openness and ALMS Analysis: Frameworks for Open Educational Resources," Open Learning: The Journal of Open and Distance Learning, 21 (2010). http://hdl.lib.byu.edu/1877/2133

${ }^{23}$ Gurell, "Measuring the Technical Difficulty," 2.

${ }^{24}$ Steven Ovadia, "Addressing the Technical Challenges of Open Educational Resources," portal: Libraries and the Academy, 19, 1 (2019): 79-93.

${ }^{25}$ Cheryl Cullier, Amy Hofer, Annie Johnson, Kathleen Labadorf, Karen Lauristen, Peter Potter, Richard Saunders, and Anita Walz. Modifying an Open Textbook: What You Need to Know (Open Textbook Network, 2016), 9.

${ }^{26}$ Kleymeer, Kleinman, and Hanss, "Reaching the Heart," 3.

${ }^{27}$ Ferguson, "Open Educational Resources," 35.

${ }^{28}$ Julie Sweetkind, Mary Lynette Larsgaard, and Tracey Erwin. "Digital Preservation of Geospatial Data,” Library Trends, 55, 2 (2006): 304-314, doi: 10.1353/lib.2006.0065.

${ }^{29}$ Linda Cantara, "Long-Term Preservation of Digital Humanities Scholarship," OCLC Systems and Services: International Digital Library Perspectives, 22, 1 (2006): 38-42, doi:10.1108/10650750610640793; Leslie Johnson, "Digital Humanities and Digital Preservation," The Signal, April 12, 2013, https://blogs.loc.gov/thesignal/2013/04/digitalhumanities-and-digital-preservation/

${ }^{30}$ Cameron Cook, "Archiving Web Content," in The Complete Guide to Personal Digital Archiving, ed. Brianna Marshall (Chicago: American Library Association, 2018), 33-55.

${ }^{31}$ Charles Watkinson, "The Academic eBook Ecosystem Reinvigorated: A Perspective from the USA," Learned Publishing, 31,3 (2018): 283.

${ }^{32}$ Watkinson, "The Academic eBook," 283. 
${ }^{33}$ Amy Kirchhoff and Sheila Morrissey, "Preserving eBooks: DPC Technology Watch Report," Digital Preservation Coalition (2014): 9,

https://www.dpconline.org/docs/technology-watch-reports/1230-dpctw14-01/file

${ }^{34}$ Johnson, "Digital Humanities."

35 Ibid

${ }^{36}$ Scholarly Publishing and Research Coalition (SPARC), "Connect OER Directory,” 2017, https://connect.sparcopen.org/directory/

${ }^{37}$ Scholarly Publishing and Research Coalition (SPARC), "Connect OER Reports," 2017, https://sparcopen.org/our-work/connect-oer/reports/

${ }^{38}$ Ovadia, "Addressing the Technical Challenges," 85.

${ }^{39}$ Ibid.

${ }^{40}$ Atenas and Havemann, "Quality Assurance," 29.

${ }^{41}$ Ovadia, "Addressing the Technical Challenges," 83. 